\title{
Perancangan Sistem Pendingin Stayrofoam Air Conditionerportable Menggunakan Thermoelectric Cooler (Elemen Peltier)
}

\author{
Moh Insan Kamil ${ }^{1}$, Ilmirizki Imaduddin ${ }^{2}$, dan Amalia Herlina ${ }^{3}$ \\ Prodi Teknik Elektro, Fakultas Teknik Universitas Nurul Jadid \\ Karanganyar Paiton Probolinggo 67291 \\ email : Mohinsank@gmail.com
}

\begin{abstract}
Abstrak - Pada penelitian ini dihasilkan perancangan dan sistem pendingin ruangan, hasil pengujian akurasi (thermoelektrik cooler, dan hygrometer). Pada hasil pengujian thermoelektrik cooler hasil rata-rata peltier didapatkan suhu $8,5^{\circ} \mathrm{C}$, peltier kedua didapatkan rata-rata $8,6^{\circ} \mathrm{C}$, peltier ketiga didapatkan rata-rata $5^{\circ} \mathrm{C}$, peltier ke empat didapatkan rata-rata $4,8^{\circ} \mathrm{C}$, peltier kelima didpatkan rata-rata $4,6^{\circ} \mathrm{C}$, dan peltier terakhir didapatkan $4,1^{\circ} \mathrm{C}$. Dan untuk hasil pengujian menggunakan hygrometer pembacaan temperatur relatif antara sensor NTC dengan hygrometer linear dengan $R^{2} \mathbf{0 , 8 0 0 4}$, dimana $R^{2}$ merupakan regresi dan dapat menunjukkan kelelitian pengukuran alat yang dibuat sebesar $80 \%$. Dari data-data yang telah dianalisa, secara umum sistem suhu pendingin ruangan styrofom menggunakan thermoelektrik cooler pada penelitian ini telah memenuhi syarat umum sebuah pengendali, dimana untuk variasi-variasi akan menghasilkan respon yang diinginkan dari sebauah sistem pendingin. Apabila ada gangguan dari luar dapat ditanggapi secara responsif dari sistem, dengan selalu berusaha mendekatkan suhu sesuai set point.
\end{abstract}

Kata kunci: Thermoelektrik Cooler, Sistem Konrol, SensorNTC, dan Hygrometer.

Abstract- This research resulted in the design and air conditioning system, the results of accuracy testing (thermoelectric cooler, and hygrometer). In the thermoelectric cooler test results, the average peltier temperature is 8.5 $o C$, the second peltier gets an average of $8.6 \mathrm{oC}$, the third peltier gets an average of $5 \mathrm{oC}$, the fourth peltier gets an average of $4.8 \mathrm{oC}$, peltier the fifth got an average of $4.6 \mathrm{oC}$, and the last peltier got $4.1 \mathrm{oC}$. And for the test results using a hygrometer, the relative temperature reading between the NTC sensor and a linear hygrometer with $\mathbf{R} 20.8004$, where $R 2$ is a regression and can show the accuracy of the measurement tool made by $80 \%$. From the data that has been analyzed, in general the styrofoam air conditioning temperature system using a thermoelectric cooler in this study has met the general requirements of a controller, where variations will produce the desired response from a cooling system. If there is interference from outside, the system can respond responsively, by always trying to bring the temperature closer to the set point.

Keywords: Thermoelectric Cooler, Control System, NTC Sensor and Hygrometer.

\section{PENDAHULUAN}

Kemajuan teknologi yang semakin pesat ditandai dengan berbagai peralatan yang sangat ramah lingkungan. Salah satu usaha pengembangan ramah lingkungan adalah penggunaan elemen peltier pada cooler box. Elemen peltier ini ramah lingkungan karena tidak menggunakan gas freon untuk proses pendinginan, sehingga tidak merusak lingkungan [1].

Pada umumnya, mesin pendingin menggunakan freon sebagai pendingin dalam siklus kerjanya. Freon merupakan salah satu syntetic refrigent atau pendingin buatan [2]. Material thermoelektrik cooling bersifat semikondukro tipe $\mathrm{p}$ dan tipe $\mathrm{n}$, material yang termasuk tipe p diantaranya Bismuth Telluride $\left(\mathrm{Bi}_{2} \mathrm{Te}_{3}\right)$, juga ada beberapa yang menggunakan Zinc Oxide $(\mathrm{ZnO})$ dengan doping tembaga $(\mathrm{Cu})$ [3].

Pada penelitian perancangan sistem pendingin styrofom air conditioner portabel, dengan memanfaatkan thermoelektrik cooler (elemen peltier sebagai pendingin pada box styrofom diharapakan dapat dijaidkan acuan untuk pengganti pendingin konvensional, dengan kelebihan dan kekurangan elemen peltier untuk bisa direkayasa dirancang yang lebih maksimal.

\section{A. Mesin Pendingin}

\section{STUDi PUSTAKA}

Mesin pendingin merupakan salah satu mesin yang mempunyai fungsi utama untuk mendinginkan zat sehingga temperaturnya lebih rendah dari temperatur lingkungan. Komponen utama dari mesin pendingin yaitu kompresor, kondensor, alat ekspansi dan evaporator, serta refrigeran sebagai fluida kerja yang bersirkulasi pada bagian-bagian tersebut. Gambar 1 memperlihatkan skema sederhana dari mesin pendingin [4]. 

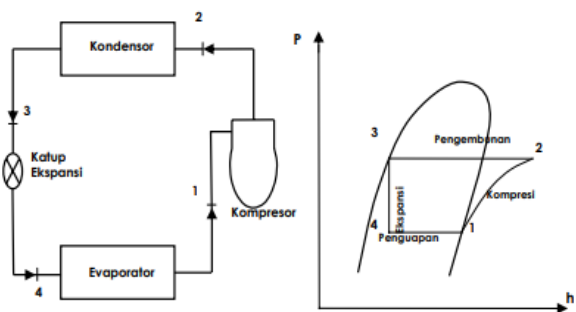

Gambar 1. Komponen Utama Mesin Pendingin dan Diagram P-h

\section{B. Pendingin Thermoelektrik}

Prinsip kerja thermoelektrik adalah berdasarkan efek seebeck, yaitu ketika arus DC dialirkan ke elemen peltier yang terdiri dari beberapa pasangan semikonduktor tipe $\mathrm{p}$ (yaitu semikonduktor yang mempunyai tingkat energi yang lebih rendah) dan tipe $\mathrm{n}$ (yaitu semikonduktor dengan tingkat energi yang lebih tinggi) akan menyebabkan salah satu sisi elemen peltier menjadi dingin (kalor diserap) dan sisi lain menjadi panas (kalor dilepas) dan senaliknya, jika arah arus dibalik. Elektron yang menghalir dari semikonduktor tipe-p ke semikonduktor tipe-n menyebabkan sisi dengin elemen peltier menjadi dingin.

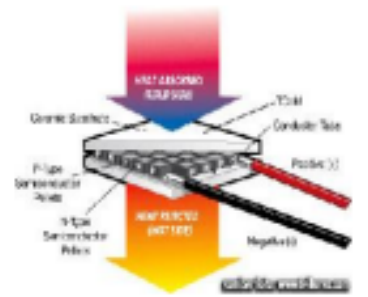

Gambar 2. Aliran Elektron Dari Tipe P ke Tipe N

Penyerapan kalor dari lingkungan terjadi pada sisi dingin lalu dibuang pada sisi panas dari modul Peltier. Sehingga nilai kalor yang dilepaskan pada sisi panas akan sama dengan nilai kalor yang diserap ditambah dengan daya yang diberikan ke modul [5].

\section{Kinerja Modul Thermoelektrik}

Dalam melakukan analisa kinerja modul Thermoelectric dapat diamati bahwa perpindahan panas yang terjadi dari beban kalor menuju sisi dingin modul termoelektrik dapat diketahui dari jumlah kalor yang dipompa oleh efek Peltier, panas yang berpindah dari sisi panas ke sisi dingin karena konduktivitas termal material Thermoelectric, dan sebagiandari total efek Joule heating yang ditimbulkan oleh arus listrik terhadap tahanan termal [6].

- Kalor yang dipompa oleh efek peltier

$$
q_{p}=a . T_{c} . I
$$

- Kalor yang berpindah karena konduktivitas termal

$$
q_{k}=K . \Delta T
$$

- Efek Joule heating yang ditimbulkan oleh arus listrik

$$
q_{j}=\frac{I^{2} \cdot R}{2}
$$

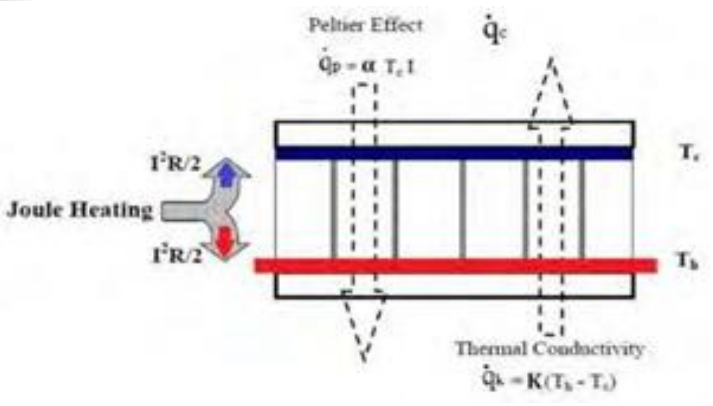

Gambar 3. Perpindahan Kalor Pada Thermoelektrik

\section{Elemen Peltier}

Elemen Pelter adalah alat yang dapat menimbulkan perbedaan suhu antara kedua sisinya jika dialiri arus listrik searah pada kedua kutub materialnya, dalam hal ini semikonduktor. Pada gambar 3 ditunjukkan bentuk fisik elemen peltier. Dala hal refrigasi, keuntungan utama dari elemen peltier adalah bagian yang bergerak atau cairan yang bersikulasi, dan ukurannya kecil serta bentuk mudah direkayasa [7].

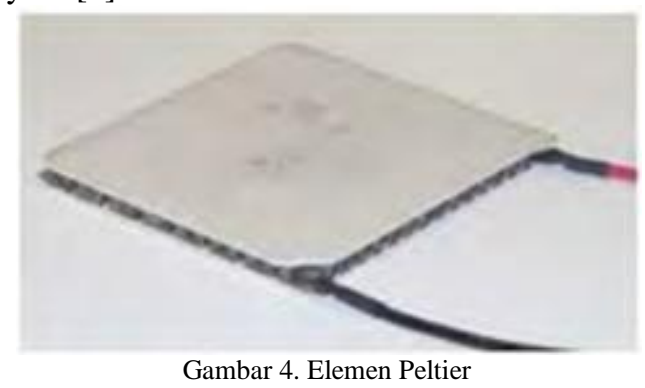

\section{E. Heatsink}

Heatsink biasanya terbuat dari aluminium, berada dalam kontak dengan sisi panas dari modul termoelektrik. Ketika positif dan negatif dari modul termoelektrik dihubungkan ke terminal positif dan negatif masingmasing dari sumber daya DC, panas akan dilepaskan oleh Modul termoelektrik sisi panas, heatsink melancarkan pembuangan panas. Heatsink biasanya adalah tahap peralihan pada Proses pemindahan panas dimana panas mengalir ke dalam heatsink dan kemudian ditransfer ke media eksternal. Umumnya heatsink termasuk konveksi bebas, konveksi paksa dan cairan dingin, tergantung pada ukuran kulkas [8].

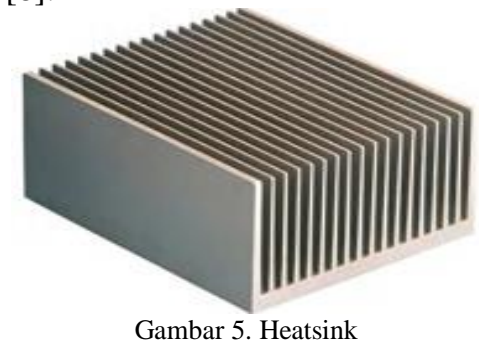

F. Kalor Yang Diserap Mesin Pendingin

Nilai kalor yang diserap oleh mesin pendingin merupakan jumlah panas yang diserap untuk menurunkan/mendinginkan suatu ruangan [9], dapat diketahu dengan rumus dibawah ini :

$$
Q=m \cdot c p \cdot \Delta T
$$

Dimana :

$$
Q=\text { Kalor yang diserap (Kcal) }
$$


$m=$ Berat dari produk yang dinginkan $(\mathrm{kg})$

$c p=$ panas jenis dari produk di atas titik beku( $\left.\mathrm{Kcal} / \mathrm{kg}{ }^{\circ} \mathrm{C}\right)$ $\Delta T=$ perubahan temperatur $\left({ }^{\circ} \mathrm{C}\right)$

\section{METODE}

Pada penelitian ini akan merancang sistem pendingin stayrofom, dengan ukuran diameter $20 \times 30 \mathrm{~cm}$. Jika Untuk menjalankan pengujian, maka dilakukan dengan merangkaikan komponen komponen yang telah di siapkan. Pada rangkaian yang tertera pada Gambar 6. Adapun Fungsi komponen rangkaian listrik cool box terdiri dari Power supplay, sensor NTC, Modul Thermostat, peltier, power suply 12 V 60 A dan terminal blok, dan Hetsink. Power suplay berfungsi untuk konverter tegangan listrik 220v (AC) ke 12v (DC), dan berfungsi untuk memberi sumber tegangan $12 \mathrm{v}$ ke terminal blok kemudian disalurkan pada komponen elektronik yang ada pada thermoelektrik paltier dan dan modul thermostat masing masing. Modul thermostat ini terdapat komponen Sensor NTC dan relay, sensor NTC ini untuk membaca temperatur pada posisi hetsink dingin paltier, dan relay ini berfungsi untuk memutuskan tegangan dari power suplay menuju pada peltier masing masing, dan relay ini akan aktiv/ ON jika temperatur NTC yang terbaca pada monitor thermostat ini sudah mencapai set poin yang diinginkan.

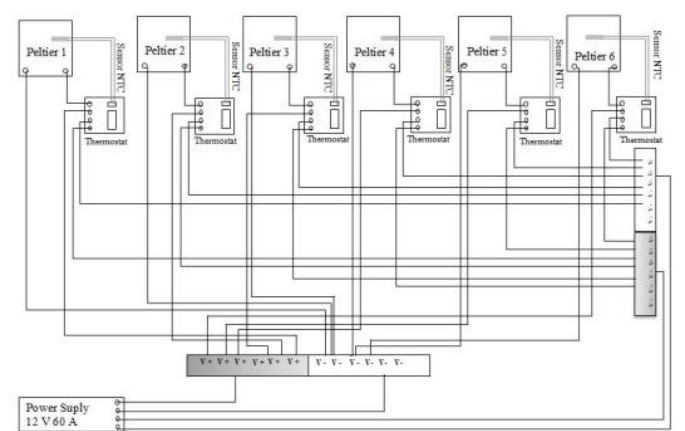

Gambar 6. Perancangan Susunan Sistem Pendingin Styrofom

Dalam menguji hasil perancangan yang dilakukan pada sistem pendingin styrofom pada gambar 7. Perancangan sistem pendingin dibuat untuk melakukan pengujian pengukuran temperatur dalam ruangan styrofom sehingga didapatkan data proses pendinginan pada styrofom. Perancangan sistem pendingin ini juga dilengkapi alat ukur hygrometer dan fan sebagai pembuang panas dari sisi peltier yang dilapisi heatsing.

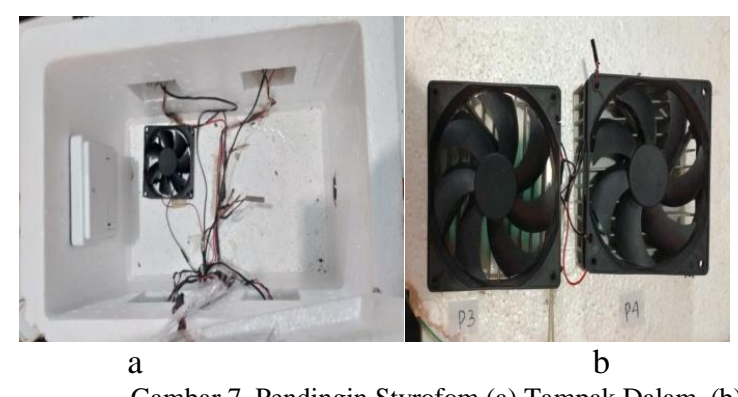

Gambar 7. Pendingin Styrofom (a) Tampak Dalam, (b) Tampak Atas

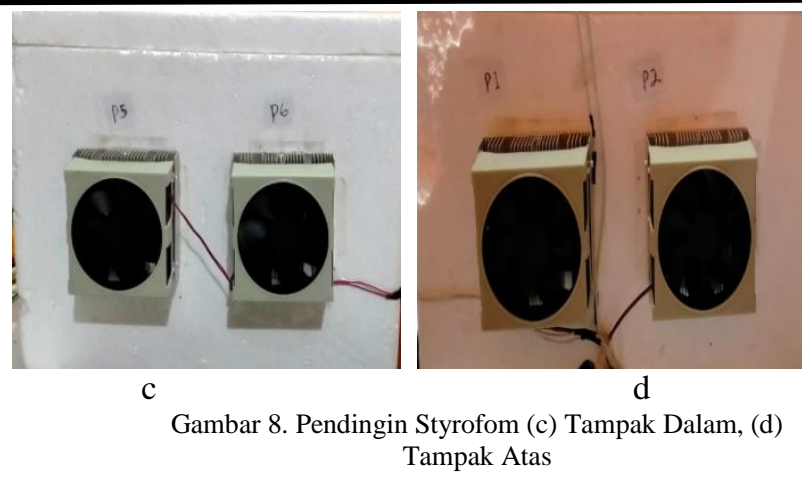

IV. HASIL DAN PEMBAHASAN

- Perancangan Pendingin Styrofom Air Conditioner Portabel

Perancangan pada penelitian ini dapat dilihat pada gambar 9 dan 10. dimana peralatan yang digunakan diantaranya, 6 peltier, 7 sensor NTC, 7 Fan, dan 6 termostat yang dirancang dijadikan satu untuk dihubungkan ke power suply yang diberikan aliran listrik untuk kebutuhan daya yang dibutuhkan.
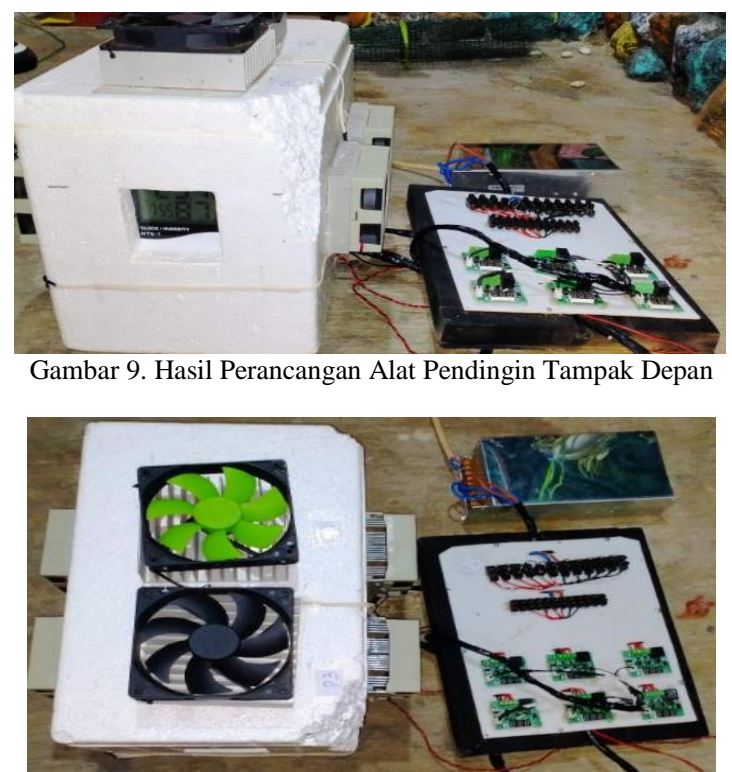

Gambar 10. Hasil Perancangan Alat Pendingin Tampak Atas

Sensor NTC berisi informasi suhu yang dihasilkan oleh peltier. Dalam penelitian tugas akhir ini 6 sensor yang diletakkan pada peltier dan 1 sensor NTC diletakkan di atas untuk mendeteksi suhu yang ada di dalam ruangan styrofom. Nilai pembacaan suhu dari sensor NTC menggunakan satuan ${ }^{\circ} \mathrm{C}$ dan untuk kalibrasi sensor NTC dengan alat ukur Hygrometer menggunakan satuan $\%$. Hasil dari suhu yang dihasilkan oleh sensor NTC terbaca di termostat.

\section{- Hasil Perancangan Sistem Pendingin}

Pada perancangan sistem pendingin styrofom air conditioner portabel menggunakan thermoelektrik cooler (elemen peltier), dapat dilihat pada gambar 11 . 


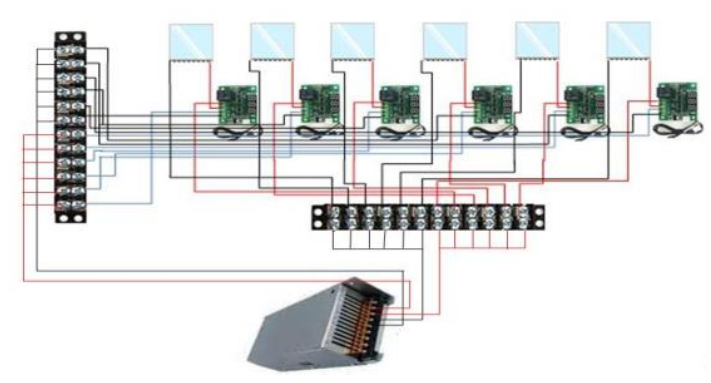

Gambar 11. Rangkaian Alat Pendingin

Pada Gambar 11. dihasilkan rangkaian sistem pendingin di mulai dari power suplay yang di jumper langsung ke 2 terminal blok yang mana 1 terminal untuk menghantarkan arus ke modul thermostat pada pin $\mathrm{K} 0$ kemudian dihubungkan ke pin thermostat K1 yang mana $\mathrm{K} 0, \mathrm{~K} 1$ itu sebagai kontak atau ON OFF 12 volt paltier, Selanjutnya Terminal blok yang kedua yaitu untuk menghubungkan power $12 \mathrm{~V}$ dan GND Modul thermostat.

\section{- Hasil Pengujian Akurasi}

\section{Hasil Pengujian Thermoelektrik Cooler}

Tujuan dari pengujian yang dilakukan adalah untuk mengetahui performance atau unjuk kerja dan mengetahui suhu dingin yang optimal pada sistem pendingin ruangan. Komponen atau peralatan pendukung diperlukan agar pengujian dapat dilakukan, peralatan tersebut berupa hygrometer. Dalam pengujian sistem pendingin ruangan ini dilakukan dengan lama waktu pengukuran suhu ruangan dari 17.00 WIB - 02.30 WIB dengan kondisi awal suhu ruangan $29^{\circ} \mathrm{C}$ sampai $20^{\circ} \mathrm{C}$. Maka dari hasil pengujian thermoelektrik cooler dapat dilihat pada tabel dibawah ini.

Tabel 1. Hasil Pengujian Thermoelektrik Cooler

\begin{tabular}{ccccccc}
\hline \multirow{2}{*}{ Jam } & \multicolumn{7}{c}{ Sensor NTC } \\
\cline { 2 - 7 } & Peltier 1 & $\begin{array}{c}\text { Pelti } \\
\text { er 2 }\end{array}$ & $\begin{array}{c}\text { Pelti } \\
\text { er 3 }\end{array}$ & $\begin{array}{c}\text { Pelti } \\
\text { er 4 }\end{array}$ & $\begin{array}{c}\text { Pelti } \\
\text { er 5 }\end{array}$ & $\begin{array}{c}\text { Pelti } \\
\text { er 6 }\end{array}$ \\
\hline 17.00 & 8,5 & $-5,7$ & 8 & 17,8 & $-5,8$ & 14,6 \\
18.00 & 8,6 & $-9,9$ & 6,13 & 16,1 & 0,42 & $-3,3$ \\
19.00 & 5,0 & $-10,6$ & 4,8 & 15,4 & $-5,8$ & $-4,5$ \\
20.00 & 4,8 & $-11,3$ & 3,8 & 14,7 & $-9,5$ & $-7,7$ \\
21.00 & 4,6 & $-11,9$ & 3,1 & 14,4 & $-10,2$ & $-6,7$ \\
22.00 & 4,1 & $-12,2$ & 3,2 & 14,4 & $-9,8$ & $-8,1$ \\
23.00 & 3,4 & $-12,9$ & 2,7 & 13,9 & $-10,6$ & 8,5 \\
00.00 & 3 & -13 & 2,3 & 13,9 & 10,8 & $-8,6$ \\
01.00 & 2,9 & $-13,6$ & 3,1 & 13,8 & $-9,7$ & $-7,4$ \\
02.30 & 3,2 & $-14,3$ & 2,2 & 15,5 & $-5,6$ & -10 \\
\hline
\end{tabular}

Dapat dilihat pada tabel 1 hasil pengujian thermoelektrik cooler dilakukan selama 9 jam 30 menit untuk mengetahui suhu ruangan di stayroform dengan menggunakan 6 peltier. Pengujian peltier dilakukan per 10 menit untuk mengetahui perubahan suhu ruangan yang terjadi di stayroform.

\section{Analisa Temperatur Thermoelektrik Cooler}

Pada tahapan ini akan dibahas tentang analisa hasil pengujian temperatur pada perancangan sistem pendingin styrofom air conditioner portabel menggunakan thermoelektrik cooler (elemen peltier). Hasil dari tabel 1 dapat dianalisa dengan grafik dibawah ini.

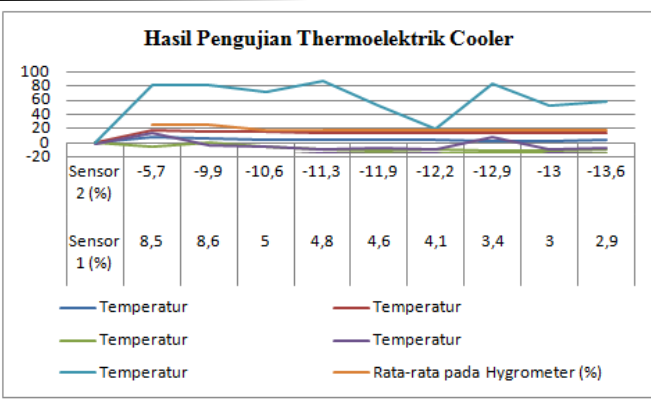

Gambar 12. Grafik Hasil Pengujian Thermoelektrik Cooler

Dari grafik diatas dapat dilihat semua titik pengujian peltier mengalami naik turun temperatur di dalam ruangan stayroform relatif sama terhadap waktu pendinginan. Pengujian terdiri dari 6 peltier dengan setiap peltier menggunakan sensor NTC, dimana pada warna biru tua menunjukkan peltier pertama, warna oranye menunjukkan peltier kedua, warna hijau menunjukkan peltier tiga, warna ungu menunjukkan peltier 4, warna biru muda menunjukkan peltier 5 , dan warna coklat menunjukkan pelter 6 .

Pengujian dilakukan pada jam 17.00 Wib dengan suhu ruangan awal $29{ }^{\circ} \mathrm{C}$ selama 9 jam 30 menit. Pada variabel pertama dilakukan pengujian per 10 menit untuk mengetahui penurunan suhu ruangan yang terjadi di stayroform. Pada pengujian pertama yang dapat dilihat pada grafik di atas dapat diketahui bahwa hasil rata-rata peltier didapatkan suhu $8,5^{\circ} \mathrm{C}$, peltier kedua didapatkan rata-rata $8,6^{\circ} \mathrm{C}$, peltier ketiga didapatkan rata-rata $5{ }^{\circ} \mathrm{C}$, peltier ke empat didapatkan rata-rata $4,8^{\circ} \mathrm{C}$, peltier kelima didpatkan rata-rata $4,6^{\circ} \mathrm{C}$, dan peltier terakhir didapatkan $4,1^{\circ} \mathrm{C}$, sampai seterusnya dapat dilihat pada tabel 4.1 .

\section{Hasil Pengujian Suhu Ruangan Menggunakan Hygrometer}

Sebelum proses pengambilan data pada suhu ruangan styrofom, maka dilakukan kalibrasi dulu. Tujuannya dikukan kalibrasi sensor adalah agar data yang ditampilkan dapat dipercaya dan akurat. Kalibrasi sensor NTC dilakukan dengan membandingkan hasil sensor NTC terhadap alat ukur hygrometer dengan tingkat ketelitian $0,5 \%$. Niali yang dihasilkan pada sensor NTC harus menunjukkan nilai sebanding antara sensor NTC dengan nilai alat ukur hygrometer. Data perbandingan dapat dilihat pada tabel 2 .

Tabel 2. Hasil Pengujian Hygrometer

\begin{tabular}{|c|c|c|c|c|c|c|c|c|}
\hline \multicolumn{7}{|c|}{ Temperatur } & \multirow{2}{*}{$\begin{array}{c}\text { Rata-rata } \\
\text { pada } \\
\text { Hygrometer } \\
(\%)\end{array}$} & \multirow{2}{*}{$\begin{array}{c}\text { Presentase } \\
\text { Ketelitian } \\
\text { Sensor } \\
(\%)\end{array}$} \\
\hline $\begin{array}{c}\text { Sensor } \\
1(\%)\end{array}$ & $\begin{array}{c}\text { Sensor } \\
2(\%)\end{array}$ & $\begin{array}{c}\text { Sensor } \\
3(\%)\end{array}$ & $\begin{array}{r}\text { Sensor } \\
4(\%)\end{array}$ & $\begin{array}{c}\text { Sensor } \\
\mathbf{5}(\%)\end{array}$ & $\begin{array}{c}\text { Sensor } \\
6(\%)\end{array}$ & $\begin{array}{l}\text { Rata- } \\
\text { rata } \\
(\%)\end{array}$ & & \\
\hline 8,5 & $-5,7$ & 8 & 17,8 & $-5,8$ & 14,6 & 82 & 26 & 84 \\
\hline 8,6 & $-9,9$ & 6,13 & 16,1 & 0,42 & $-3,3$ & 81 & 25 & 54 \\
\hline 5,0 & $-10,6$ & 4,8 & 15,4 & $-5,8$ & $-4,5$ & 72 & 19 & 46 \\
\hline 4,8 & $-11,3$ & 3,8 & 14,7 & $-9,5$ & $-7,7$ & 87 & 19 & 53 \\
\hline 4,6 & $-11,9$ & 3,1 & 14,4 & $-10,2$ & $-6,7$ & 52 & 19 & 36 \\
\hline 4,1 & $-12,2$ & 3,2 & 14,4 & $-9,8$ & $-8,1$ & 20 & 19 & 20 \\
\hline 3,4 & $-12,9$ & 2,7 & 13,9 & $-10,6$ & 8,5 & 84 & 19 & 52 \\
\hline 3 & -13 & 2,3 & 13,9 & $-10,8$ & $-8,6$ & 53 & 18 & 35 \\
\hline 2,9 & $-13,6$ & 3,1 & 13,8 & $-9,7$ & $-7,4$ & 58 & 18 & 38 \\
\hline 3,2 & $-14,3$ & 2,2 & 15,5 & $-5,6$ & -10 & 55 & 27 & 41 \\
\hline
\end{tabular}

Data dari sensor NTC pada tabel 2, terlihat pembacaan antara sensor 1, 2, 3, 4, 5, dan 6 cukup berbeda. Hal ini disebabkan oleh penempatan posisi sensor NTC 
yaitu partikel-partikel air yang dihasilkan oleh peltier ke permukaan styrofom menyebabkan tekanan uap air di udara jenuh, sehingga temperatur relatif cukup besar

\section{Analisa Temperatur Pengujian Hygrometer}

Untuk analisa hasil pengujian temperatur hygrometer dapat dilihat pada gambar 12, dibawah ini.

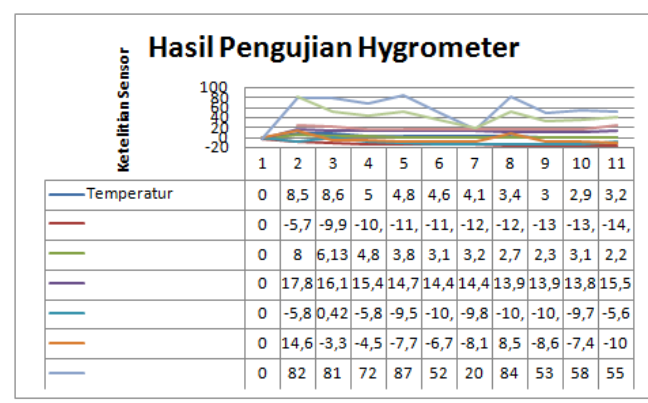

Gambar 13. Grafik Hasil Pengujian Hygrometer

Pada gambar 13, grafik dapat dilihat pembacaan temperatur relatif antara sensor NTC dengan hygrometer linear dengan $R^{2} 0,8004$, dimana $R^{2}$ merupakan regresi dan dapat menunjukkan kelelitian pengukuran alat yang dibuat sebesar $80 \%$.

\section{- Hasil Pembahasan Keseluruhan}

Hasil dari perancangan penelitian tugas akhir adalah akusisi data suhu pada ruangan syroform dan sistem pendingin menggunakan thermoelektrik cooler (peltier). Perancangan ini merupakan kolaborasi perangkat keras yang diimplementasikan sebagai portabel sisten pendingin dan perangkat lunak yang diimplemetasikan dalam pengolahan dan pemrosesan data. Sistem pendingin yang terjadi dalam poratabel akuisisi data merupakan kontrol loop tertutup.

Thermistor NTC dan Thermistor PTC adalah Komponen Elektronika yang berfungsi sebagai sensor pada rangkaian Elektronika yang berhubungan dengan Suhu (Temperature). Suhu operasional Thermistor berbeda-beda tergantung pada Produsen Thermistor itu sendiri. Pada pengujian Thermistor NTC dengan Hygrometer didapatkan pembacaan yang dpaat diketahui keakurasiannya. Dari gambar 9 grafik didapatkan pembacaan sensor NTC dengan hygrometer linear dengan $R^{2} \quad 0,8004$, dimana $R^{2}$ merupakan regresi dan dapat menunjukkan kelelitian pengukuran alat yang dibuat sebesar $80 \%$.

Dari data-data yang telah dianalisa, secara umum sistem suhu pendingin ruangan styrofom menggunakan thermoelektrik cooler pada penelitian ini telah memenuhi syarat umum sebuah pengendali, dimana untuk variasivariasi akan menghasilkan respon yang diinginkan dari sebauah sistem pendingin. Apabila ada gangguan dari luar dapat ditanggapi secara responsif dari sistem, dengan selalu berusaha mendekatkan suhu sesuai set point.

\section{KESIMPULAN}

Pada penelitian perancangan sistem pendingin ruangan stayrofoam air conditioner portabel menggunakan thermoelektric cooler (elemen peltier), didapatkan beberapa kesimpumpulan, diantaranya:

1. Pada penelitian ini dihasilkan perancangan dan sistem pendingin ruangan, hasil pengujian akurasi (thermoelektrik cooler, dan hygrometer).

2. Pada hasil pengujian thermoelektrik cooler hasil ratarata peltier didapatkan suhu $8,5{ }^{\circ} \mathrm{C}$, peltier kedua didapatkan rata-rata $8,6{ }^{\circ} \mathrm{C}$, peltier ketiga didapatkan rata-rata $5{ }^{\circ} \mathrm{C}$, peltier ke empat didapatkan rata-rata 4,8 ${ }^{\circ} \mathrm{C}$, peltier kelima didpatkan rata-rata $4,6{ }^{\circ} \mathrm{C}$, dan peltier terakhir didapatkan $4,1{ }^{\circ} \mathrm{C}$. Dan untuk hasil pengujian menggunakan hygrometer pembacaan temperatur relatif antara sensor NTC dengan hygrometer linear dengan $\mathrm{R}^{2} 0,8004$, dimana $\mathrm{R}^{2}$ merupakan regresi dan dapat menunjukkan kelelitian pengukuran alat yang dibuat sebesar $80 \%$.

3. Dari data-data yang telah dianalisa, secara umum sistem suhu pendingin ruangan styrofom menggunakan thermoelektrik cooler pada penelitian ini telah memenuhi syarat umum sebuah pengendali, dimana untuk variasi-variasi akan menghasilkan respon yang diinginkan dari sebauah sistem pendingin. Apabila ada gangguan dari luar dapat ditanggapi secara responsif dari sistem, dengan selalu berusaha mendekatkan suhu sesuai set point.

\section{REFERENSI}

[1] Eko Yudiyanto, Satworo Adiwidodo, R. N. Akhanu Takwin. 2020 "Pemanfaatan Pelter Sebagai Sistem Pendingin Untuk Medicine Cooler Box". SNITT-Politeknik Negeri Balikpapan. ISBN: 978602-251450-2-5.

[2] Frima Gandi, Meqorry Yusfi. 2016. "Perancangan Sistem Pendingin Air Menggunakan Elemen Peltier Berbasis Mikrokontroler Atmega8535". Jurnal Fisika Unand Vol. 5, No. 1, Januari 2016. ISSN 2302-8491.

[3] Lukman Nulhakim. 2017. "Uji Unjuk Kerja Pendingin Ruangan Berbasis Thermoelektrik Cooling". Jurnal SIMETRIS, Vol 8 Nol 1 April 2017. ISSN: 2252-4983.

[4] Khairil Anwar. 2010. "Efek Beban Pendingin Terhadap Performa Sistem Mesin Pendingin”. Jurnal SMARTek, Vol. 8 No.3. agustus 2010: 203-214.

[5] J. Delly, M, Hasbi, I.F. Alkhoiron, "Studi Penggunaan Modul Thermoelektrik Sebagai Sistem Pendingin Portable", Jurnal Enthalpy Vol. 1, No.1 Mei 2016, EIssn:2502-8944.

[6] Jaworski, Christopher M. "Opportunites for Thermoelectric Energy Conversion in Hybrid Vehicles". The Ohio State University. Department of Mechanical Engineering. 2007.

[7] Djafar, Zuryati. (2018), "Pengantar Termoelektrik". Karya Tulis Ilmiah Program Doktor Departemen Teknik Mesin Universitas Indonesia.

[8] Onoroh, F, Chukuneke, J, L, and Itoje, H, J, "Performance Evaluation of a Thermoelectric Refrigerator", International Journal of Engineering and Innovative Technology (IJEIT) Volume 2, Issue 7, January 2013.

[9] Ardhi Kamal Haq, Juhri Hendrawan, Ahmad Hasan Asyari. 2017. "PENGUJIAN KINERJA COUPLE THERMOELEKTRIK SEBAGAI PENDINGIN PROSESOR". Prosiding SNATIF K e-4 Tahun 2017 ISBN: 978-602-1180-50-1. 